\title{
RELATIONAL RISKS FOR GUANXI BOUNDARY SPANNERS IN CHINESE-FOREIGN BUSINESS INTERACTIONS
}

\author{
Annie H. Liu, Victoria University of Wellington, New Zealand \\ Hongzhi Gao, Victoria University of Wellington, New Zealand
}

\begin{abstract}
Guanxi boundary-spanners are important gate openers and relationship facilitators for foreign firms and managers considering doing business in a close-knit Chinese society. With increasing attention on proper way of doing business in the Chinese society, Western businesses are keen to connect with beneficial guanxi network. However, little attention has been given to the significant risks that guanxi boundary spanners assume in working with both guanxi insiders and outsiders. This research gap ignores one of the most important contexts for the guanxi boundary spanner: the risks of the role are often the result of in-group social norms embedded in Confucius values that can undermine new or out-group relationships. The purpose of the current research is to evaluate the underlying and intertwined social norm conflicts and strengths of guanxi ties, which create relational risks for guanxi boundary-spanners and their patrons. Applied Social Penetration Theory and Guanxi concentric circle analogy, the current study interviewed thirty-three experts from a global expatriate network with using critical incident techniques (CIT). Our findings confirm that guanxi boundary spanners often evaluate two key factors to assess relational risks: (A) the level of social norm conflict between foreign out-group and guanxi in-group and (B) the strength of his/her guanxi with the in-group members. These two key factors were used to identify resulting four quadrants: Shameless Foreign Supporter, Profit Exploiter, Unneeded Middleman, Information Trader.
\end{abstract}

Contributing to relationship marketing and international business literature, this study is among the first to empirically investigate the relational risks guanxi boundary-spanners assumed when assisting foreign businesses connecting guanxi network. Our findings provide new information to aid international marketing/business executives to: (1) identify key factors driving relational risks, (2) understand relational risks typologies guanxi brokers undertaken, (3) develop strategies to mitigate these risks, and thereby, (4) enter the guanxi-inside group by means that develop positive, long-term relationships with the subject Chinese businesses.

References available upon request 